\title{
EFFICACY OF THE USE OF THE MCKENZIE AND VOJTA METHODS TO TREAT DISCOPATHY-ASSOCIATED SYNDROMES IN THE PEDIATRIC POPULATION
}

\section{ARKADIUSZ ŻURAWSKI ${ }^{1,2}$, WOJCIECH KIEBZAK ${ }^{1,2}$, ANNA ZMYŚLNA ${ }^{1,2}$, JUSTYNA POGORZELSKA ${ }^{1,2}$, IRENEUSZ KOTELA ${ }^{1}$, TOMASZ J. KOWALSKI ${ }^{3}$, ZBIGNIEW ŚLIWIŃSKI ${ }^{1,4}$, and GRZEGORZ ŚLIWIŃSKI ${ }^{5}$}

\author{
${ }^{1}$ Jan Kochanowski University, Kielce, Poland \\ Faculty of Medicine and Health Sciences, Institute of Physiotherapy \\ ${ }^{2}$ Provincial Integrated Hospital in Kielce, Kielce, Poland \\ Świętokrzyskie Center for Pediatrics \\ ${ }^{3}$ Wye Valley Foundation Trust, Hereford, United Kingdom \\ Department of Orthopedic Surgery, Hereford County Hospital \\ ${ }^{4}$ Rehabilitation Center, Zgorzelec, Poland \\ ${ }^{5}$ Technical University in Dresden, Dresden, Germany \\ Institute of Biomedical Engineering, Faculty of Electrical and Computer Engineering
}

\begin{abstract}
Objectives: This paper evaluates the efficacy of using the McKenzie and Vojta methods for patients with low back pain and the use of the DIERS Formetric 4D system as an objective diagnostic tool. Material and Methods: The study enrolled 28 patients aged 15-17 years old. The patients were hospitalized at the Department of Orthopedics and Traumatology of the Świętokrzyskie Center for Pediatrics in Kielce with a diagnosis of back pain associated with a discopathy. The patients were rehabilitated according to the McKenzie and Vojta methods. Assessment by means of the DIERS Formetric system had taken place before the first therapy session and on the day that pain was eliminated to evaluate trunk inclination, angle of thoracic kyphosis, angle of lumbar lordosis, lateral deviation, trunk torsion, surface rotation and pelvic obliquity. Pain intensity and change in pain intensity over time were assessed by means of a numerical rating scale. Results: Pain intensity was reduced to 0 over 3-12 days. The study participants demonstrated reduction in anterior trunk inclination of the mean value at $1.83^{\circ}$. The angle of thoracic kyphosis was also reduced by $7.95^{\circ}$. The angle of lordosis increased by $7.6^{\circ}$. The lateral spinal curvature was reduced by $8.92 \mathrm{~mm}$. There was a reduction of $4.64^{\circ}$ in trunk torsion. Surface rotation was reduced by $1.61^{\circ}$ and pelvic obliquity was reduced by $3.78^{\circ}$. Conclusions: In discopathic patients, postural parameters comprising trunk inclination, angle of thoracic kyphosis, angle of lumbar lordosis, lateral deviation, trunk torsion, vertebral rotation and pelvic obliquity fail to reach Hartzmann's physiological reference ranges. A therapeutic intervention based on the Vojta and McKenzie methods may normalize the posture to physiological reference ranges and is effective in the treatment of patients with back pain. The DIERS system is an objective tool for tracing the effects of therapy in patients with back pain. Int J Occup Med Environ Health. 2019;32(1):33-41
\end{abstract}

Key words:

DIERS, Vojta, McKenzie, lordosis, kyphosis, back pain

Received: December 2, 2017. Accepted: May 14, 2018.

Corresponding author: Arkadiusz Zurawski, Jan Kochanowski University, Faculty of Medicine and Health Sciences, Institute of Phisiotherapy, al. IX Wieków Kielc 19A, 25-317 Kielce, Poland (e-mail: azurawski@onet.eu). 


\section{INTRODUCTION}

Back pain is becoming increasingly prevalent in both the adult and pediatric populations. Most commonly, the site of pain is the lumbar segment of the spine. The shift from an active to sedentary life style is believed to be a main underlying cause of back pain, contributing to abnormalities in the activity of muscles, ligaments and joints [1,2]. Any anatomical structure as well as nervous system abnormalities may be a cause of pain. Contributing factors in back pain include overweight, pro-gravity posturing and co-existing medical conditions, including cancer [2,3]. Different sources present different data regarding the incidence/prevalence of back pain. The use of a diversity of diagnostic methods and groups of different characteristics leads to significant differences in epidemiological data both in Poland and globally [4-6]. The literature describes non-specific back pain, characterized by a variety of incidence/prevalence patterns and a multifactorial etiology [6-8]. Still, back pain is a recurrent condition with periods of symptomatic exacerbation and remission, and the symptoms tend to become progressively more chronic. Chronic pain alters neuromuscular control and performance of movement, producing functional disorders. Patients with chronic back pain demonstrate disorders of balance, postural control, co-ordination and muscle endurance and reduced proprioception of the trunk position [9]. Effective treatment of back pain should be based on a detailed diagnostic evaluation. The complexity of episodes of organic and functional back pain makes diagnosis considerably difficult, necessitating the use of MRI, CT and conventional radiography scans. The DIERS Formetric 4D system is an additional diagnostic modality serving to make the diagnosis more objective. It utilizes visual stereographic measurements. The formetric examination is characterized by significant reproducibility and sensitivity. It does not involve exposure to Röntgen radiation, which is an advantage. The formetric measurement of the course of spinous processes and vertebral rotation demonstrates a high degree of compatibility with CT-based calculations of the Raimondi angle [10,11].

Based on an appropriately selected diagnostic tool and an insightful analysis, an optimum rehabilitation program based on neurophysiological methods may be developed for a given patient. In the study of pediatric patients, authors used the McKenzie method which incorporated a system of diagnostic and therapeutic actions that were of importance for a detailed assessment of the causes of pain. The Vojta approach was also used. This method serves to restore normal motor patterns and correct postural defects through the use of both fundamental systems of facilitation ("reflex creeping" and "reflex rolling") to produce a change in the position of the center of gravity and help the patient assume an erect position and maintain body balance and a coordinated posture. A special selection of physiotherapeutic interventions and preventive measures plays a significant role as adjuncts to the therapy [3,12-14].

This paper offers an objective evaluation of postural abnormalities in children with back pain. Significant deviations were noted with regard to the angle of lordosis, lateral spinal curvature, trunk torsion and vertebral rotation, pelvic orientation and the gait cycle.

\begin{abstract}
Aim
This paper evaluates the efficacy of using the McKenzie and Vojta methods in patients with low back pain and the use of the DIERS Formetric 4D system as an objective diagnostic tool.
\end{abstract}

\section{MATERIAL AND METHODS}

The study enrolled 28 patients (10 boys and 18 girls) aged 15-17 years old. The patients were hospitalized at the Department of Orthopedics and Traumatology of the Świętokrzyskie Center for Pediatrics in Kielce with a diagnosis of back pain associated with a discopathy confirmed 
by CT assessment. History taking and physical examination did not reveal coexisting medical conditions that could have contributed to the symptoms reported by the patients. The pain was of a mechanical nature, which was caused by the intervertebral pressure.

The inclusion criteria involved the age 15-17 years, a diagnosis of lumbosacral disc disease, and an overt consent to participate given by the patient and his/her legal guardian. The exclusion criteria comprised chronic pain (> 1 month), coexisting conditions with similar symptomatology, use of analgesics within $24 \mathrm{~h}$ preceding the first and last examination and termination of therapy or noncompliance with therapeutic instructions.

Pain intensity was rated on an 11-item numerical rating scale (NRS) where a mark of 0 corresponded to no pain and a mark of 10 corresponded to the most severe pain possible.

The DIERS examination with precise measurement of the parameters was performed before the first therapy session and on the day the pain was completely eliminated, the interval ranging 3-12 days $(\mathrm{M}=5)$.

Parameters were assessed by means of the DIERS Formetric 4D system. Markers were used for improving measurement precision. The DIERS Formetric Average examination was carried out for each patient to assess spinal alignment. The following parameters were evaluated:

- trunk inclination: the angle between the line connecting the $\mathrm{C} 7$ and $\mathrm{L} 5$ spinous processes and the vertical projection of the $\mathrm{C} 7$ spinous process,

- angle of thoracic kyphosis: the angle formed by the apex of the thoracic kyphosis and the C7 and Th12 spinous processes,

- angle of lumbar lordosis: angle formed by the apex of lumbar lordosis and the Th12 and L5 spinous processes,

- lateral deviation: distance between the apex of the lateral curvature and the body's axis of symmetry,
- trunk torsion: trunk rotation relative to the line connecting the posterior superior iliac spines,

- surface rotation: difference in skin height overlying the spinal transverse processes,

- pelvic obliquity: angle formed by the line connecting the posterior superior iliac spines and a line perpendicular to the body's axis of symmetry.

An individual therapy session involved the use of therapeutic techniques for the lumbar spine according to McKenzie and a combination of global patterns based on the Vojta approach. A significant role was also played by patient reeducation regarding the maintenance of an optimum body posture for rehabilitation purposes. The physiotherapist worked with each patient for about $20 \mathrm{~min} 3$ times a day. Patients were instructed to practice the prescribed therapy every $2 \mathrm{~h}$. Both the hospitalized patients and their legal guardians had been informed in detail about the therapeutic approach and educated about the therapeutic techniques. All patients and their legal guardians were acquainted with the study methodology and provided their informed consent to participate.

Student's t-test for dependent samples was used for analyzing the study findings statistically.

\section{RESULTS}

The CT scans obtained on the day of admission in all patients revealed the presence of intervertebral disc protrusions of 3-6 mm with impression of the meningeal sac. The protrusions were seen in the lumbar spine (Table 1).

During the baseline examination, the patients rated pain intensity at 6-8 pts on a numerical rating scale (Table 1). On the day of self-assessment of pain intensity, the patients were not exposed to analgesic medication.

Following the therapy (a combination of the McKenzie and Vojta techniques with detailed patient reeducation), pain subsided completely (NRS 0) within 3-12 days after beginning of the therapy. The duration of treatment of different patients was different. There was no relationship between 
Table 1. Rotation at individual L-S levels, size of protrusions and pain intensity at the beginning of treatment of patients aged 15-17 years old in the Department of Orthopedics and Traumatology of the Świętokrzyskie Center for Pediatrics in Kielce, Poland

\begin{tabular}{|c|c|c|c|c|c|c|c|c|c|}
\hline \multirow{2}{*}{$\begin{array}{c}\text { Patient } \\
\text { no. }\end{array}$} & \multicolumn{4}{|c|}{$\begin{array}{c}\text { Rotation } \\
{\left[^{\circ}\right]}\end{array}$} & \multicolumn{4}{|c|}{$\begin{array}{l}\text { Protrusion size } \\
\text { [mm] }\end{array}$} & \multirow{2}{*}{$\begin{array}{c}\text { Pain intensity (NRS) - } \\
\text { examination } 1\end{array}$} \\
\hline & L1 & $\mathrm{L} 2$ & L3 & L4 & L1-L2 & L2-L3 & L3-L4 & L4-L5 & \\
\hline 1 & -1.8 & -2 & -2.7 & -1.5 & 0 & 3 & 4 & 0 & 7 \\
\hline 2 & -4.3 & 0.3 & 1.3 & 0.1 & 0 & 0 & 5 & 0 & 7 \\
\hline 3 & -0.7 & -2.2 & -1.3 & 0 & 0 & 4 & 3 & 0 & 6 \\
\hline 4 & -2.1 & -0.7 & -0.8 & -0.2 & 4 & 0 & 3 & 0 & 6 \\
\hline 5 & -8.8 & -7.6 & -5.8 & -1 & 5 & 5 & 3 & 0 & 8 \\
\hline 6 & 4.8 & 4.1 & 3.3 & 1.5 & 4 & 4 & 3 & 0 & 7 \\
\hline 7 & -2.2 & 0.1 & 1 & -0.4 & 5 & 0 & 3 & 0 & 7 \\
\hline 8 & -4.5 & -4.2 & -3.7 & -2.1 & 6 & 5 & 0 & 0 & 8 \\
\hline 9 & -3.3 & -5.9 & -5.4 & -2.3 & 0 & 6 & 4 & 0 & 6 \\
\hline 10 & -2.7 & -3.7 & -3 & 0.5 & 3 & 4 & 5 & 0 & 7 \\
\hline 11 & -3.4 & -4.1 & -3 & -1.4 & 0 & 3 & 0 & 0 & 6 \\
\hline 12 & -7.9 & -6.3 & -3.6 & -1.6 & 6 & 4 & 4 & 0 & 7 \\
\hline 13 & 0.8 & 0 & -1.5 & -2.2 & 0 & 0 & 3 & 5 & 6 \\
\hline 14 & -4.8 & -3.1 & -0.8 & -0.4 & 4 & 3 & 0 & 0 & 6 \\
\hline 15 & -2.9 & -3.9 & -1.8 & 1 & 0 & 5 & 0 & 0 & 7 \\
\hline 16 & 0.2 & -1.6 & -1.7 & -0.2 & 0 & 5 & 6 & 0 & 7 \\
\hline 17 & -0.2 & -2 & -4 & -3.7 & 0 & 0 & 4 & 6 & 8 \\
\hline 18 & -4.3 & -3.9 & -4.5 & -0.9 & 3 & 0 & 5 & 0 & 6 \\
\hline 19 & -5.4 & -5.5 & -3.5 & -1.3 & 4 & 5 & 0 & 0 & 7 \\
\hline 20 & -2.9 & -1.3 & 0 & 0.2 & 4 & 3 & 0 & 0 & 6 \\
\hline 21 & -5.5 & -4.9 & -3.3 & -1.5 & 4 & 4 & 3 & 0 & 6 \\
\hline 22 & -4.2 & -5.7 & -3.8 & -0.4 & 5 & 6 & 0 & 0 & 8 \\
\hline 23 & -1.6 & -0.2 & 1.4 & 0.5 & 0 & 0 & 5 & 0 & 8 \\
\hline 24 & -0.3 & 1.1 & 0.4 & -0.9 & 0 & 6 & 3 & 0 & 6 \\
\hline 25 & -4.6 & -4.9 & -3.2 & 0 & 5 & 4 & 3 & 0 & 6 \\
\hline 26 & -2.4 & -1.4 & -1.8 & -1 & 4 & 3 & 3 & 0 & 6 \\
\hline 27 & -3.8 & -3.9 & -3.1 & -0.7 & 5 & 5 & 3 & 0 & 7 \\
\hline 28 & -2.3 & -1 & -0.4 & 0.1 & 0 & 0 & 4 & 6 & 8 \\
\hline
\end{tabular}

NRS - numerical rating scale.

the time of recovery and the size of discopathy. Patients did not take analgesics during the entire treatment. The elimination of pain produced a change in DIERS parameters.
The study participants demonstrated reduced anterior trunk inclination by $1.83^{\circ}\left(2.87^{\circ}\right.$ at baseline vs. $1.04^{\circ}$ at final examination) on average. This difference was statistically significant at $\mathrm{p}<0.05$ (Table 2). 
Table 2. Changes of parameters in 28 patients aged 15-17 years old during the treatment in the Department of Orthopedics and Traumatology of the Świętokrzyskie Center for Pediatrics in Kielce, Poland

\begin{tabular}{lccc}
\hline \multicolumn{1}{c}{ Parameter } & \multicolumn{2}{c}{ Change revealed during the examination } & \multirow{2}{*}{$\mathrm{p}$} \\
\cline { 2 - 3 } & baseline & final & $<0.05$ \\
\hline Trunk inclination $\left[^{\circ}\right]$ & 2.87 & 1.04 & $<0.05$ \\
Angle of thoracic kyphosis $\left[^{\circ}\right]$ & 39.08 & 31.14 & $<0.05$ \\
Angle of lumbar lordosis $\left[^{\circ}\right]$ & 28.88 & 36.48 & $<0.05$ \\
Lateral deviation $[\mathrm{mm}]$ & 7.21 & -1.71 & $<0.05$ \\
Trunk torsion $\left[^{\circ}\right]$ & 3.83 & -0.81 & $<0.05$ \\
Surface rotation $\left[{ }^{\circ}\right]$ & 4.72 & 3.11 & $<0.05$ \\
Pelvic obliquity $\left[^{\circ}\right]$ & 1.84 & -1.96 & \\
\hline
\end{tabular}

The angle of thoracic kyphosis was reduced by $7.95^{\circ}\left(39.08^{\circ}\right.$ at baseline vs. $31.14^{\circ}$ at final examination). This difference was statistically significant at $\mathrm{p}<0.05$ (Table 2 ).

The angle of lordosis increased by $7.6^{\circ}\left(28.88^{\circ}\right.$ at baseline vs. $36.48^{\circ}$ at final examination). This difference was statistically significant at $\mathrm{p}<0.05$ (Table 2).

The lateral curvature of the spine ("lateral deviation") was reduced by $8.92 \mathrm{~mm}(7.21 \mathrm{~mm}$ at baseline vs. $-1.71 \mathrm{~mm}$ at final examination; the minus sign preceding the value indicates hypercorrection of the lateral curvature). This difference was statistically significant at $\mathrm{p}<0.05$ (Table 2).

Rotation of the trunk relative to the body axis ("trunk torsion") was reduced by $4.64^{\circ}$ (3.83 at baseline vs. $-0.81^{\circ}$ at final examination; the minus sign preceding the value indicated trunk rotation to the opposite side than at baseline). This difference was statistically significant at $\mathrm{p}<0.05$ (Table 2). Vertebral rotation ("surface rotation") was also investigated. Upon completion of the treatment, this parameter was reduced by $1.61^{\circ}\left(4.72^{\circ}\right.$ at baseline vs. $3.11^{\circ}$ at final examination). This difference was statistically significant at $\mathrm{p}<0.05$ (Table 2).

The pelvic orientation ("pelvic obliquity") also changed by $3.78^{\circ}\left(1.84^{\circ}\right.$ at baseline vs. $1.96^{\circ}$ at final examination); the minus sign preceding the value indicates pelvic inclination to the opposite side than at baseline). This difference was statistically significant at $\mathrm{p}<0.05$ (Table 2).

\section{DISCUSSION}

Back pain is a social problem all over the world regardless of the particular countries or populations studied as well as economic or social conditions. Both acute and chronic symptoms predominate. The prevalence of back pain has prompted research in this area, focusing mostly on the location, frequency and intensity of the pain and the patients' quality of life [15-18]. It is estimated that approximately $70-85 \%$ of the population have experienced an episode of back pain [19,20]. Research on back pain in the pediatric population dates back to the 1980's, when this issue was first brought to the fore by Salamin, whose work was followed by an avalanche of papers on back pain in the pediatric population, with special attention to the lumbo-sacral segment [21,22]. The literature stresses the non-specific nature of back pain in the pediatric population and its multifactorial etiology, and the prevalence figures given vary widely [5,6]. In a prospective study, Kjaer et al. found that symptoms of degenerative disc disease were present in one third of their study population of 13-year-old children [22].

Preliminary epidemiological studies indicate that $11-71 \%$ of children experience back pain. According to Watson et al. [23], the problem affects approximately $24 \%$ of children aged 11-14 years old, Skaggs et al. [24], however, writes that this problem affects up to $37 \%$ of children. 
Approximately $40 \%$ of the pediatric population experience at least one episode of back pain, with $13 \%$ experiencing recurrent pain, and $10 \%$ of school-age children reporting intermittent pain. Back pain is most often associated with injury to the intervertebral disc and degeneration of intervertebral discs and facet joints [25-27]. Imaging studies reveal herniation and degenerative lesions to be the most common causes of pain [28]. Intervertebral disc injury in the pediatric population predominantly affects one disc, occurring most commonly at L4/L5 and L5/S1 [29,30]. It is believed that the prevalence of back pain in children increases with age [31]. Numerous epidemiological studies have shown a correlation between the occurrence of back pain in children and physical activity. A sedentary life style and postural defects contribute substantially to the presence of body pain [32].

The current literature includes few papers combining research on discopathy-associated pain in the pediatric population and selected therapeutic and diagnostic approaches. There are relatively more publications on nonspecific back pain in children [5,6]. However, there is no significant discussion regarding the efficacy of a combination of the Vojta and McKenzie approaches in discopathyassociated back pain in children.

The literature on the Vojta method is most often concerned with the therapy of children in the neonatal period and infancy. Authors concentrate on the diagnosis and therapy of early disorders of CNS function and muscle tone [33-36]. Steffan [37] claims that the Vojta approach may be used in the treatment of idiopathic scoliosis. The main aim of the Vojta method is to effect a normal motor pattern through the use of basic facilitation systems. The result is improved function of the proprioceptive and vestibular systems, which in turn improves trunk stability.

The literature on the McKenzie method includes papers on the diagnosis and therapy of all spinal segments, and especially the lumbar spine. Authors consider the preva- lence and elimination of back pain. There are also papers comparing the McKenzie method and manual therapies $[13,38,39]$. In this study, the intention of the McKenzie method is to use appropriate diagnostic protocols that will be beneficial for reducing pain in the pediatric population.

In view of its complex pathomechanism, back pain gives rise to numerous diagnostic and therapeutic difficulties. Non-invasive imaging techniques include the DIERS Formetric examination, which may reveal abnormalities in body posture, gait cycle, balance or loading in early disease. The DIERS system is being increasingly used both for imaging posture and for non-invasive evaluation of treatment outcomes [10,40-43]. This study used the DIERS Formetric 4D and pedogait systems for verifying postural abnormalities in children with back pain and known discopathy lesions. Authors have presented in an objective manner significant changes in the angle of lordosis, lateral spinal curvature, trunk and vertebral rotation, as well as changes in pelvic orientation and the gait cycle. The medical market now offers the DIERS system as a tool for noninvasive and precise assessment of posture in both static and dynamic positions. There is a need for further studies of the DIERS system to present a wider array of applications of this device.

\section{CONCLUSIONS}

In discopathic patients, postural parameters comprising trunk inclination, angle of thoracic kyphosis, angle of lumbar lordosis, lateral deviation, trunk torsion, vertebral rotation and pelvic obliquity fail to reach Hartzmann's physiological reference ranges.

A therapeutic intervention based on the Vojta and McKenzie methods may normalize the posture to physiological reference ranges and is effective in the treatment of patients with back pain.

The DIERS system is an objective tool for tracing the effects of the therapy in patients with back pain. 


\section{REFERENCES}

1. Pinto R, Ferreira P, Kongsted A, Ferreira M, Maher C, Kent P. Self-reported moderate-to-vigorous leisure time physical activity predicts less pain and disability over 12 months in chronic and persistent low back pain. Eur J Pain. 2014;18(8):11908, https://doi.org/10.1002/j.1532-2149.2014.00468.x.

2. Holth HS, Werpen HKB, Zwart JA, Hagen K. Physical inactivity is associated with chronic musculoskeletal complaints 11 years later: Results from the Nord-Trøndelag Health Study. BMC Musculoskelet Disord. 2008;9:159, https://doi.org/10. 1186/1471-2474-9-159.

3. Dwornik M, Białoszewski D, Kiebzak W, Łyp M. Correlation of selected physical examination findings in patients with chronic lumbosacral pain. Ortop Traumatol Rehabil. 2007;9(3):297-309.

4. Adamczyk A, Kiebzak W, Wilk-Frańczuk M, Śliwiński Z. Effectiveness of holistic physiotherapy for low back pain. Ortop Traumatol Rehabil. 2009;11(6):562-76.

5. Shirani-Adl A, El-Rich M, Pop DG, Parnianpour M. Spinal muscle forces, internal loads and stability in standing under various postures and loads - Application of kinematicsbased algorithm. Eur Spine J. 2005;14(4):381-92, https://doi. org/10.1007/s00586-004-0779-0.

6. Pellisé F, Balagué F, Rajmil L, Cedraschi C, Aguirre M, Fontecha CG, et al. Prevalence of low back pain and its effect on health-related quality of life in adolescents. Arch Pediatr Adolesc Med. 2009;163(1):65-71, https://doi.org/10.1001/arch pediatrics.2008.512.

7. Dobosiewicz K. [Back pain with non organic cause-biomechanical, neurophysiological and psychosocial determinants]. Neurol Dziec. 2006;15(30):51-7. Polish.

8. Drozda K, Lewandowski J, Górski P. Back pain in lower and upper secondary school pupils living in urban areas of Poland. The case of Poznań. Ortop Traumatol Rehabil. 2011;13(5):489-503.

9. Jones GT, Macfarlane GJ. Epidemiology of low back pain in children and adolescents. Arch Dis Child. 2005;90:312-6, https://doi.org/10.1136/adc.2004.056812.
10. Mangone M, Raimondi P, Paoloni M, Pellanera S, Michele A, Renzo S, et al. Vertebral rotation in adolescent idiopathic scoliosis calculated by radiograph and back surface analysis-based methods: Correlation between the Raimondi method and rasterstereography. Eur Spine J. 2013;22(2):36771, https://doi.org/10.1007/s00586-012-2564-9.

11. Vrtovec T, Pernus F, Likar B. Determination of axial vertebral rotation in MR images: Comparison of 4 manual and a computerized method. Eur Spine J. 2010;19(5):774-81, https://doi.org/10.1007/s00586-010-1340-y.

12. Charlusz M, Gasztych J, Irzmanski R, Kujawa J. Comparative analysis of analgesic efficacy of selected physiotherapy methods in low back pain patients. Ortop Traumatol Rehabil. 2010;12(3):225-36.

13. Waqqar S, Shakil-ur-Rehman S, Ahmad S. McKenzie treatment versus Mulligan sustained natural apophyseal glides for chronic mechanical low back pain. Pak J Med Sci. 2016;32(2):476-9, https://doi.org/10.12669/pjms.322.9127.

14. Garcia AN, Costa LDM, Hancock M, Costa LOP. Identifying patients with chronic low back pain who respond best to mechanical diagnosis and therapy: Secondary analysis of a randomized controlled trial. Phys Ther. 2016;96(50):62330, https://doi.org/10.2522/ptj.20150295.

15. Borenstein DG. Epidemiology, etiology, diagnostic evaluation, and treatment of low back pain. Curr Opin Rheumatol. 2001;13:128-34, https://doi.org/10.1097/00002281-2001 03000-00006

16. Bjerkreim I, Steen H, Brox JI. Idiopathic scoliosis treated with Cotrel-Dubousset instrumentation: Evaluation 10 years after surgery. Spine. 2007;32(19):2103-10, https://doi.org/10. 1097/BRS.0b013e318145a54a.

17. Glassman S, Gornet MF, Branch C, Polly D Jr, Peloza J, Schwender JD, et al. MOS short form 36 and Oswestry Disability Index outcomes in lumbar fusion: A multicenter experience. Spine J. 2006;6(1):21-6, https://doi.org/10.1016/j.spinee.2005.09.004.

18. Paprocka J, Jamroz E, Głuszkiewicz E, Klimczak A, Kluczewska E, Marszał E. [Back pain in children]. Wiad Lek. 2008;61(7-9):183-9. Polish. 
19. McMeeken J, Tully E, Stillman B, Nattrass C, Bygott I-L. The experience of back pain in young Australians. Man Ther. 2001;6(4):213-20, https://doi.org/10.1054/math.2001. 0410 .

20. Burton AK, Balagué F, Cardon G, Eriksen HR, Henrotin Y, Lahad A, et al. How to prevent low back pain. Best Pract Res Clin Rheumatol. 2005;19(4):541-55, https://oi. org/10.1016/j.berh.2005.03.001.

21. Shehab DK, Al-Jarallah KF. Nonspecific low-back pain in Kuwaiti children and adolescents: Associated factors. J Adolesc Health. 2005;36(1):32-5, https://doi.org/10.1016/ j.jadohealth.2003.12.011.

22. Kjaer P, Wedderkopp N, Korsholm L, Lenouef-Yde C. Prevalence and tracking of back pain from childhood to adolescence. BMC Musculoskelet Disord. 2011;12:98-108, https:// doi.org/10.1186/1471-2474-12-98.

23. Watson KD, Papageorgiou AC, Jones GT, Taylor S, Symmons DPM, Silmman A, et al. Low back pain in schoolchildren: Occurrence and characteristics. Pain. 2002;97(1):8792, https://doi.org/10.1016/S0304-3959(02)00008-8.

24. Skaggs DL, Early SD, D’Ambra P, Tolo VT, Kay RM. Back pain and backpacks in school children. J Pediatr Orthop. 2006;26(3):358-63, https://doi.org/10.1097/01.bpo. 0000217723.14631.6e.

25. Petersen S, Brulin C, Bergström E. Recurrent pain symptoms in young schoolchildren are often multiple. Pain. 2006;121(1):145-50, https://doi.org/10.1016/j.pain.2005. 12.017 .

26. Hoy D, Brooks P, Blyth F, Buchbinder R. The epidemiology of low back pain. Best Pract Res Clin Rheumatol. 2010;24(6):769-81, https://doi.org/10.1016/j.berh.2010. 10.002 .

27. Kjaer P, Leboeuf-Yde C, Sorensen JS, Bendix T. An epidemiological study of MRI and low back pain in 13-year-old children. Spine. 2005;30(7):798-806, https://doi.org/10.1097/ 01.brs.0000157424.72598.ec.

28. Faingold R, Saigal G, Azouz EM, Morales A, Albuquerque PA. Imaging of low back pain in children and adolescents.
Semin Ultrasound CT MR. 2004;25(6):490-505, https://doi. org/10.1053/j.sult.2004.09.005.

29. Mustard CA, Kalcevich C, Frank JW, Boyle M. Childhood and early adult predictors of risk of incident back pain: Ontario Child Health Study 2001 follow-up. Am J Epidemiol. 2005;162(8):779-86, https://doi.org/10.1093/aje/kwi271.

30. Wedderkopp N, Kjaer P, Hestbaek L, Korsholm L, Leboeuf C. High-level physical activity in childhood seems to protect against low back pain in early adolescence. Spine J. 2009;9(2):134-41, https://doi.org/10.1016/j.spinee. 2008.02.003.

31. Wedderkopp N, Andersen LB, Froberg K, Leboeuf-Yde C. Back pain reporting in young girls appears to be pubertyrelated. BMC Musculoskelet Dis. 2005;6:52-7, https:/doi. org/10.1186/1471-2474-6-52.

32. Lynch AM, Kashikar-Zuck S, Goldschneider KR, Jones BA. Psychosocial risks for disability in children with chronic back pain. J Pain. 2006;7(4):244-51, https://doi.org/10.1016/ j.jpain.2005.11.001.

33. Jung MW, Landenberger M, Jung T, Lindenthal T, Philippi H. Vojta therapy and neurodevelopmental treatment in children with infantile postural asymmetry: A randomised controlled trial. J Phys Ther Sci. 2017;29(2):301-6, https:// doi.org/10.1589/jpts.29.301.

34. Banaszek G. [Vojta's method as the early neurodevelopmental diagnosis and therapy concept]. Przegl Lek. 2010;67(1):67-76. Polish.

35. Gajewska E, Samborski W. [Application of Vojta's method for early detection of developmental disturbances in very low birthweight infants with regard to Apgar score and asymmetric body positions]. Ann Acad Med Stetin. 2006;52 Suppl 2:101-4. Polish.

36. Meholjić-Fetahović A. [Importance of early rehabilitation using the Vojta method in symptomatic high risk infants]. Med Arh. 2005;59(4):224-6. Bosnian.

37. Steffan K. [Physical therapy for idiopathic scoliosis]. Orthopade. 2015;44(11):852-8, https://doi.org/10.1007/s00132015-3174-0. German. 
38. De Campos TF, Maher CG, Clare HA, da Silva TM, Hancock MJ. Effectiveness of McKenzie method-based self-management approach for the secondary prevention of a recurrence of low back pain (SAFE Trial): Protocol for a pragmatic randomized controlled trial. Phys Ther. 2017;97(8):799806, https://doi.org/10.1093/ptj/pzx046.

39. Calloni SF, Huisman TA, Poretti A, Soares BP. Back pain and scoliosis in children: When to image, what to consider. Neuroradiol J. 2017;30(5):393-404, https://doi. org/10.1177/1971400917697503.

40. Wilczyński J, Pedrycz A, Mucha D, Ambroży T, Mucha D. Body posture, postural stability, and metabolic age in patients with Parkinson's disease. Biomed Res Int. 2017;2017:3975417, https://doi.org/10.1155/2017/3975417.
41. Sung DH, Yoon SD, Park GD. The effect of complex rehabilitation training for 12 weeks on trunk muscle function and spine deformation of patients with SCI. J Phys Ther Sci. 2015;27(3):951-4, https://doi.org/10.1589/jpts.27.951.

42. März K, Adler W, Matta RE, Wolf L, Wichmann M, Bergauer B. Can different occlusal positions instantaneously impact spine and body posture? A pilot study using rasterstereography for a three-dimensional evaluation. J Orofac Orthop. 2017;78(3):221-32, https://doi.org/10.1007/s00056016-0073-x.

43. Książek-Czekaj A, Wiecheć M, Śliwiński G, Śliwiński Z. [Monitoring the results of scoliosis improvement using the Diers system]. Fizjoter Pol. 2016;16(3):124-34. Polish.

This work is available in Open Access model and licensed under a Creative Commons Attribution-NonCommercial 3.0 Poland License - http://creativecommons.org/ licenses/by-nc/3.0/pl/deed.en. 